\title{
Firm size distribution and growth*
}

\author{
Patrizio Pagano and Fabiano Schivardi \\ Bank of Italy, Research Department
}

October 2000

\begin{abstract}
We empirically characterize the sectoral distribution of firm size for a set of European countries, finding substantial differences in the size distribution within sectors. We then study the relationship between productivity growth at the sectoral level and size structure. We find a positive and robust association between average firm size and growth. We tackle the question of why size should matter for growth, considering the role of innovative activity, to construct a test based on the differential effect of size structure on growth according to different indicators of R\&D intensity. Our results indicate that larger average size fosters productivity growth because it makes possible to take advantage of all the increasing returns associated with $\mathrm{R} \& \mathrm{D}$. We finally argue that our test can be interpreted as a test of reverse causality, which lends support to the view of firm size having a causal impact on growth.
\end{abstract}

Keywords: Firm Size, Growth, RESD.

JEL classification:L11, L16, O30, O40.

\footnotetext{
${ }^{*}$ We thank Chiara Bentivogli, Andrea Brandolini, Paola Caselli, Antonio Ciccone, Juan Dolado, Andrea Gerali, Luigi Guiso, Marco Magnani, Xavier Sala-i-Martin, Sandro Trento and partecipants at the CREI-EC workshop held at UPF on June 5-6, 2000, at seminars at Ente Einaudi and the Bank of Italy, for comments and stimulating discussions. Marco Chiurato and Antonio Covelli provided valuable research assistance. We are solely responsible for any mistake. The opinions expressed in this paper do not necessarily reflect those of the Bank of Italy. Address: via Nazionale 91, 00184 Rome - Italy. E-mail: pagano.patrizio@insedia.interbusiness.it; schivardi.fabiano@insedia.interbusiness.it.
} 


\section{Introduction}

The process of European integration has spurred a great deal of attention on the question of differences in the economies of the countries participating in the European Union (EU). A substantial amount of work has been done on the national peculiarities in terms of sectorial specialization (Amiti, 1997; Bugamelli, 1999). Less is known on the differences in the industrial structure within sectors, at least on a solid quantitative ground. This paper takes a particular aspect of the industrial structure - that is firm size distribution - and, merging statistical information from different sources, studies the differences in size across European countries at the sectoral level and their effects on growth.

The study of the determinant of the steady-state distribution of firms has a long tradition in economics. Classical theories of size structure concentrated on technical factors, stressing the role of returns to scale and of the efficient scale of operation as the fundamental determinant of size (Viner, 1932). Overwhelming empirical evidence in terms of both a persistent dispersion in the cross-sectional distribution of firm size in an industry and of a certain stability in the stochastic pattern of evolution of size over time at the firm level (Gibrat's law of independent increments) has challenged this view and prompted the formulation of theories that could account for such regularities. Modern theories of firm size distribution assume that firms are heterogeneous along some dimension, typically efficiency, which has a direct impact on their equilibrium size. In such theories, the shape of the production function at the firm level is only one of the factors determining the industry equilibrium structure, which will depend on a multiplicity of factors, such as regulation, level of economic development, size of the market and so on. ${ }^{1}$ This implies that national differences in terms of institutions,

\footnotetext{
${ }^{1}$ In Lucas (1978), the size of a firm is detemined by the ability of the entrepreneur, with more able entrepreneurs optimally choosing a larger scale of operation and with entrepreneurial ability distributed randomly in the population. He shows that, if the elasticity of substitution between capital and labor is smaller than one, average size is positively correlated with the level of developement (i.e. capital per-capita) of the economy. Jovanovic (1982) builds a model in which the optimal size of the firm is determined by a productivity parameter drawn upon entering and unknown to the firm, which learns about it during its life cycle. The model delivers a series of predictions in line with empirical evidence both on the evolution of firm size at the individual level and on the size distribution. Hopenhayn (1992) considers a similar model in which the productivity parameter is known, but evolves as a random process over time. He relates the exogenous characteristics of the industry, such as the entry cost, the overall size of demand and the stochastic process for the productivity parameter to the steady state distribution of firms and to the process of entry and exit in the market. Ericson and Pakes (1995), Pakes and
} 
such as regulation in the product and the labor markets, taxation and development of the financial sector can lead to substantial differences in the size distribution of firms, even in the presence of similar production technologies.

We do not directly tackle the problem of the determinants of size structure at the national level, but rather take it as given in our analysis. Our primary goal is to investigate the effects of the predetermined firm size structure on growth. Using a data set of Eurostat on firm size, we document the existence of relevant differences in size structures among European countries. A relevant part of such differences might be due to national characteristics, especially in terms of regulation and of tax treatments, which might induce a bias towards a certain size structures over others. ${ }^{2}$ We find that countries with a given overall size structure tend to be characterized both by a larger share of employment in sectors that are "naturally" close to such structure and by a distortion toward such structure within sectors. This makes us confident that the comparison of size measures across countries is not invalidated by potential differences in measurement methods. Furthermore, we decompose the overall differences in mean size into a share attributable to sectoral specialization and another one due to size differences within sectors, finding a relevant role for the latter.

Once we have shown that there is a large degree of variability across countries in the size distribution within industries, we move on to considering whether differences in the size structure influence growth at the sectoral level. Theories of growth, based on the constant returns to scale assumption, have traditionally neglected the role of size structure. However, size might have relevant effects on dynamic efficiency and therefore on growth. For example, as recognized already by Schumpeter (1934), innovative activity could grow more than proportionally with size. ${ }^{3}$ Moreover, large firms might

McGuire (1994) endogenize the productivity parameter, assuming that its evolution is (stochastically) determined by the investment choices of the firms, and study the interaction of firms in determining the stochastic distribution of firms' size, the evolution of the industry and of the firm at the induvidual level.

${ }^{2}$ For example, Davis and Henrekson (1999) show that the Swedish tax system and regulatory framework have induced a firm population biased toward large firms. It is often argued that in Italy the regulatory framework has induce the opposite bias, both because some regulations apply only to firms above a certain employment threshold and because it is easier for small firms to elude regulation and to avoid taxation. Kumar, Rajan and Zingales (1999), using a previous release of the dataset used in this paper, explain differences in firm size mainly with country specific characteristics, stressing the role of the institutions that regulate the economic environment, such as the judicial system and the level of development of the financial system.

${ }^{3}$ The surge of a literature focusing on knowledge spillovers (see for example Audtresch, 1998) has challanged the assertion that the firm is the relevant entity to study R\&D. This 
be better at exploiting the possibilities offered by a given innovation. Recent theories of endogenous growth have tried to incorporate these considerations in models that determine simultaneously size distribution, $R \& D$ and growth (Peretto, 1999a). ${ }^{4}$

To our knowledge, there is very little empirical work studying the role of size structure on growth ${ }^{5}$. We try to fill this gap. We consider how productivity growth in the nineties at the sectoral level for a set of European countries has been influenced by the size distribution of firms in the sector. Our results show that there is a positive correlation between average size and productivity growth. Moreover, we also find some evidence of a negative contribution of size dispersion on growth; if dispersion is taken as a proxy of market concentration, this finding can be interpreted as an indication of a positive effects of competition on investment and therefore growth.

We finally directly address the question of why firm size should matter for growth, considering its effect on R\&D activities, which, as stressed by many papers in the endogenous growth literature, is the main engine of productivity growth. To this end, we construct a test in the spirit of Rajan and Zingales (1998) and conclude that size structure influences growth through $\mathrm{R} \& \mathrm{D}$ activities and .that this result is robust with respect to the problem of reverse causality that plagues most of the empirical literature on growth.

The rest of the paper is organized as follow. In Section 2 we document differences in size structure for seven large European countries. The following section contains the growth regressions analysis, while Section 4 illustrate the test to discriminate the relevant channel trough which size

literature argues that the proximity of firms induces substantial technological spillovers, which are not taken into account when considering firms in isolation. For example, in Italy the industrial districts, characterized by a large number of small, geographically close, similar firms among which relevant information flows occcur (Guiso and Schivardi, 1999), might constitute an alternative model of organization based on small interacting firms with external economies with respect to one based on large firms that internalize the economies of scale in R\&D. We neglect this aspect in this paper, leaving the consideration of its implications to future work.

${ }^{4}$ For this two channel, the correct unit of analysis is the firm rather than the plant, because R\&D activity can be coordinated at the firm level.

${ }^{5}$ The only study we came across is a paper by Carree and Thurik (1998). For a sample of european manufacturing sectors, they regress the growth in overall production on the employment share of large firms in 1990 and find a negative correlation only after giving greater weight to industries with a large number of employee. Our study considers a different time span and expecially concentrates on growth in labor productivity and not in total output or overall employment, which is the relevant variable for the evolution of per capita income. As a consequence, our results should not be interpreted in terms of employment creation or overall growth, particularly over the short run. 
influences growth. Section 5 concludes.

\section{Size differential decomposition}

In this section we perform a descriptive analysis of size structure at the sectoral level for a set of European countries. Comparing firm size across countries is a tricky task, because it involves defining the boundaries of a firm in a consistent way. This problem is at the basis of the relatively little rigorous work that has been done on the subject. In recent years, the lack of comparable data has been partially filled for Europe by a periodic report of Eurostat, Enterprises in Europe. The most recent report, issued in 1998, contains data on the size structure in 1994-1995 for eighteen European countries, with breakdown by sector of activity according to the two digit Nace Rev.1 classification. The information on size structure is organized in five size classes in terms of number of employees (0,1-9, 10-49, 50-249, $250+$ ), for which a series of variables, among which the total employment and the number of firms, is supplied. ${ }^{6}$ The unit of analysis is the enterprise, defined as "the smallest group of legal units producing goods or services and constituting an autonomous economic entity" (European Commission, 1998). The first size class contains firms with no employees, whose inclusion in the definition of firm might be questioned. However, all our results are robust with respect to the exclusion of such class, also due to the fact that our measure of size, as explained later, weights observations according to their contribution to total employment. Following the classification scheme of the dataset, our measure of size is employment, which seems preferable to other indicators, such as turnover or sales, that critically depend on the intensity of usage of intermediate inputs.

Our aim in this section is to investigate how different size structures are among European countries. To this aim, we select the eight countries that, because of data availability, will be used in the econometric analysis of the next section (Germany, France, the UK, Italy, Spain, Finland, Denmark and Sweden). They account for approximately $85 \%$ of EU15 GDP. We consider the size structure in 1994, replacing with data from 1995 or 1993 when those for 1994 are not available.

As noted before, one problem that emerges in comparing the firm size across countries is that the definition of firm might differ, thus leading to a potential bias in the size comparison. This problem is partially accounted

\footnotetext{
${ }^{6}$ For a detailed description of the SME (Small and Medium Enterprises) database see Enterprises in Europe (1998).
} 
for by the fact that our data come from a unique data set, so that the accounting procedures have been harmonized as much as possible. To further tackle this problem, together with the size analysis we perform a sectoral specialization analysis. As noted by Davis and Henrekson (1999), if a country is characterized by a set of policies that tend to favor a particular size structure, one should find both a distortion toward such structure for each sector and a higher employment is sectors that are "naturally" characterized by such structure. Measures of sectoral specialization, based on the share of workers in each sector, are less problematic in terms of differences in definitions across countries. Given that we expect that countries distortions go in the same direction for both indicators, if we find that the results from the size analysis are in line with those of the sectoral specialization, we will be confident that measured size differences correspond to actual differences rather than to differences in measurement methods.

We set out our statistical workhorses. As a summary statistic of size we use "coworker mean" (Davis and Henrekson, 1999), that is average size within a class weighted by employment share of the class. The coworker mean represents the number of workers at the average place of employment of a randomly chosen worker. With respect to a simple arithmetic mean, it weights each firm's contribution to the average in relation to its own size, therefore smoothing out the contribution of very small firms. ${ }^{7}$ This statistic is particularly well suited to our goals, because in our econometric specification the dependent variable will be the growth rate of labor productivity, which is calculated using the same weighting scheme as the coworker mean.

For sector $i$ in country $j$, define $e m p_{i j}^{c}$ as employment in class size $c$, $u_{i n} s_{i j}^{c}$ as the number of units, $e m p_{i j}$ and units $_{i j}$ as respectively total employment and total number of units in sector $i$ in country $i$. The within class average size is calculated as

$$
s_{i j}^{c}=e m p_{i j}^{c} / \text { unit }_{i j}^{c}
$$

The employment share in size class $c$ in terms of sectoral employment is

$$
\omega_{i j}^{c}=e m p_{i j}^{c} / e m p_{i j}
$$

\footnotetext{
${ }^{7}$ As an exaple, consider three sectors, one with 2 firms with 50 employees each, one with 1 firm with 99 and another with 1 employee, the third with 1 firm with 100 employee. The arithmetic means are 50, 50 and 100, while the coworker mean are 50, 98.02 and 100, making sectors 2 and 3 much closer than 1 and 2 .
} 
while the employment share of sector $i$ in terms of total employment in country $j$ is

$$
\omega_{i j}=\frac{\sum_{c} e m p_{i j}^{c}}{\sum_{i} \sum_{c} e m p_{i j}}=\frac{e m p_{i j}}{e m p_{j}}
$$

We define the average firm size in sector $i$ in country $j$ as

$$
s_{i j}=\sum_{c} \omega_{i j}^{c} s_{i j}^{c}
$$

and the average firm size in country $j$ as

$$
s_{j}=\sum_{i} \omega_{i j} s_{i j}
$$

Before applying these definitions to the data, we need to take into account differences both in the sectoral specialization pattern and in the size distribution of firms that arise directly from some exogenous specificity of each country and not from the interaction of country characteristics with market forces. For example, the share of people employed in mining and extraction is clearly dependent on the presence of natural resources in the country in question. Moreover, extraction activity is often subject to ad hoc regulations at the national level. Similarly, some countries have legal monopolies in some sectors, often publicly owned. This feature tends to distort both the average size and the share of people employed in such sectors, because public monopolies have often been used as sources of employment, with little connection to the optimal employment level. We would like our measures to be as independent as possible from such factors, and restrict our attentions to sectors were both employment and size structure are determined by the response of the markets to the institutional environment. We therefore exclude the following sectors form the analysis: mining, public utilities (electricity, water, land transport, water transport, air transport, post and telecommunication) and health. For the remaining sectors, we aggregate the two digit industries at the classification level reported in Table 1 and 2, with the aggregation procedure described in Appendix 1.

Table 1 compares the size distribution for the eight European countries selected. The first column reports the average size for the EU15 aggregate, with sectors ordered increasingly. This average value partially nets out national peculiarities and is used as a benchmark. The other columns report 
the size for each nation as a ratio to the EU15 averages, so that a value above one for country $i$ in sector $j$ indicates that such sector in that country is characterized by an average size larger than the EU15 average.

The ranking of sectors is as expected, with light manufacturing, services and construction characterized by a small average size, chemical, petroleum, finance and transportation equipment at the other extreme and food and trade around the average value. Between the smallest (Real Estate) and the largest (Transportation Equipment) there is a difference of a factor of almost 20. The table shows that there are sizeable differences among countries as well. Germany and the UK have the largest overall mean size, which is approximately $60 \%$ above the EU15 value, Sweden is $17 \%$ above, Finland $10 \%$, France and Denmark have approximately the same average size as the reference, while Spain and Italy are well below the EU15 value, with their average firm size equal, respectively, to $63 \%$ and $57 \%$ of the EU15 value.

The table also gives a preliminary answer to the question of the role of sectoral specialization vs. idiosyncratic country aspects in determining the overall average firm size. If the average size within sector tends to be similar across countries, then the overall size differences should be explained by the fact that some countries are more specialized in sectors characterized by a small average size and vice versa. If this were the case, we would expect the values in Table 1 to be concentrated around one. If, on the contrary, the size differences were explained mainly by national factors which induce a consistent bias in size within sectors, then we would expect the countries with an overall value above (below) the EU15 average to be characterized by values generally above (below) one. The table shows that within sector differences are important: indeed, the rows display large variations, indicating that the same sector can be characterized by very different size structures in different countries. By computing the standard deviation by row, we find that the sectors that have a most disperse size structure across our set of countries are Hotels \& Restaurants, Wood, Construction and Trade. Quite interestingly, all these sectors are non-manufacturing, which suggests that in manufacturing technological factors have a stronger role in determining optimal scale, reducing the effects of national peculiarities.

In terms of within countries differences, results are less clear-cut. The four large economies of the monetary union show quite a consistent pattern: for Italy and Spain almost all sectors are characterized by average size below the reference, ${ }^{8}$ while the opposite is true for Germany. This would

\footnotetext{
${ }^{8}$ For Italy, this is true in all sectors, showing a remarkeably consistent tendency to a smaller size.
} 
Table 1: Firm size in percetage of EU15 average

\begin{tabular}{lccccccccc}
\hline \hline & eu15 & $\mathrm{de}$ & $\mathrm{dk}$ & $\mathrm{es}$ & $\mathrm{fi}$ & $\mathrm{fr}$ & $\mathrm{it}$ & $\mathrm{se}$ & $\mathrm{uk}$ \\
\hline Real Estate & 81.66 & 0.76 & 0.22 & 0.37 & 0.94 & 0.91 & & 1.32 & \\
Wood & 103.96 & 1.90 & 1.75 & 0.34 & 3.21 & 0.68 & 0.21 & 1.63 & 0.93 \\
Leather & 105.10 & 0.48 & & & 0.77 & 2.05 & 0.51 & 0.47 & 2.21 \\
Construction & 106.72 & 1.23 & 1.17 & 1.06 & 1.86 & 1.32 & 0.38 & 3.36 & 0.86 \\
Textile & 175.35 & 1.86 & 0.61 & 0.65 & 1.06 & 0.95 & 0.48 & 0.49 & 1.96 \\
Hotel\&Rest. & 182.68 & 0.83 & 0.71 & 0.33 & 1.31 & 0.84 & 0.43 & 0.78 & 3.56 \\
Other Serv. & 204.85 & 1.40 & & 1.22 & 2.44 & 0.72 & 0.68 & 1.08 & 1.38 \\
Business Services & 254.28 & 1.14 & 1.12 & 0.63 & 0.77 & 1.40 & 0.30 & 0.70 & 1.23 \\
Pap.\&Pub. & 300.65 & 1.57 & 1.63 & 0.51 & 2.99 & 0.72 & 0.60 & 1.28 & 0.97 \\
Metal Prod. & 305.03 & 1.55 & 0.45 & 0.59 & 1.71 & 1.05 & 0.48 & 1.22 & 0.90 \\
Non-met. Prod. & 319.66 & 1.84 & 1.16 & 0.50 & 0.79 & 1.35 & 0.44 & 0.81 & 1.38 \\
Food & 338.66 & 0.91 & 1.95 & 0.58 & 1.68 & 0.84 & 0.75 & 1.69 & 2.46 \\
Trade & 343.04 & 1.35 & 1.11 & 0.44 & 0.63 & 0.76 & 0.16 & 0.62 & 2.91 \\
Transport & 347.03 & 1.57 & 0.51 & 0.60 & 1.02 & 1.32 & 0.70 & 0.89 & 1.35 \\
Rubber & 394.55 & 1.65 & 0.50 & 0.77 & 0.67 & 1.29 & 0.44 & 0.53 & 0.72 \\
Machinery & 406.08 & 1.33 & 1.09 & 0.56 & 0.89 & 1.44 & 0.94 & 1.09 & 0.92 \\
Other Manuf. & 532.43 & 2.00 & 0.36 & 0.11 & 0.32 & 0.31 & 0.09 & 0.22 & 0.30 \\
Chemical & 728.99 & 1.72 & 0.94 & 0.43 & 1.06 & 0.87 & 0.70 & 0.84 & 1.07 \\
Elett. Mach. & 780.51 & 1.49 & 0.30 & 0.46 & 0.78 & 0.79 & 0.52 & 1.48 & 0.62 \\
Finance & 1163.84 & 0.94 & 0.66 & 1.15 & 0.92 & 1.03 & & 1.53 & 1.55 \\
Petroleum & 1196.54 & 1.40 & & & & 1.15 & 0.87 & & \\
Transp. Equip. & 1742.63 & 1.93 & 0.31 & 0.67 & 0.42 & 1.14 & 0.88 & 0.84 & 0.72 \\
Total & 336.33 & 1.58 & 0.97 & 0.68 & 1.06 & 0.98 & 0.42 & 1.13 & 1.58 \\
\hline & & & & & & & & &
\end{tabular}

indicate that national characteristics are a fundamental determinant of the size structure even controlling for sectoral specialization. For Finland, Sweden and the UK, instead, the higher overall size is accompanied by a more disperse pattern at the sectoral level, which suggests that in these cases the national specificities do not have a symmetric effect on all sectors. Indeed, these are also the countries with the highest standard deviation by column.

To check for the robustness of our results with respect to differences in measurement methods, we move on to considering sectoral specialization. As argued before, if a country's environment tend to privilege (say) small size, then this should also induce a proportionally higher employment share in sectors where technological factors favor the small size. Therefore, we should expect that countries with a smaller size within sectors should also be 
characterized by a higher employment share in sectors with a small average size in the reference EU15 (i.e. sectors in the top rows of Table 1). Table 2 summarizes the sectoral specialization of each country in relation to the EU15 average; to allow an easy comparison with the previous table, sectors are ranked in the same order as before, that is in ascending order in terms of average size at the EU15 level. In accordance with the previous table, the first column reports the actual values for the EU15 aggregate, that is the percentage of employment in each sector. For each country, an entry above one indicates that the country is more specialized in that sector than the EU15 average. The table indicates that there are important differences in the national specialization. For example, the share of employment in Leather for Italy is more than three times as large as the EU15 average, that for Textile more than two times; these two sectors are instead well below the reference value in Germany, Denmark and Sweden.

To control for the existence of a consistent pattern of specialization within country towards sector with "naturally" larger mean size, we regress the values in Table 2 on the log of the average sectoral size in for the EU15 for each country separately. A positive value of the coefficient indicates that the country tends to be more specialized in sectors characterized by naturally larger firms. Results of the regressions, reported in Table 3, show that, in accordance with what seen before, out of six countries with an average size significantly different from the reference, the relationship is significant for the three large monetary union economies, with Germany characterized by a specialization in sectors with a higher average size and Italy and Spain with lower. For the other three countries, the coefficient is instead not statistically significant.

Up to now we have shown that both the sectoral specialization patterns and the national peculiarities within sectors have a role in explaining overall size differences across Europe. Now we want to obtain a quantitative measure of the role of each of them. Using the values in Tables 1 and 2, we can decompose the size differential from the benchmark into the following components:

$$
\begin{aligned}
s_{j}-\bar{s} & =\sum_{i} \omega_{i j} s_{i j}-\sum_{i} \bar{\omega}_{i} \bar{s}_{i} \\
& =\sum_{i}\left(\omega_{i j}-\bar{\omega}_{i}\right) s_{i j}+\sum_{i}\left(s_{i j}-\bar{s}_{i}\right) \bar{\omega}_{i}+\sum_{i}\left(s_{i j}-\bar{s}_{i}\right)\left(\omega_{i j}-\bar{\omega}_{i}\right) \\
& =\Delta_{\omega}+\Delta_{s}+\Delta_{\omega s}
\end{aligned}
$$

where, as before, $s_{i j}$ is the average size in sector $i$ in country $j, \omega_{i j}$ is the 
Table 2: Sectoral distribution of employment as share of Eu15 average

\begin{tabular}{lccccccccc}
\hline \hline & eu15 & $\mathrm{de}$ & $\mathrm{dk}$ & $\mathrm{es}$ & $\mathrm{fi}$ & $\mathrm{fr}$ & $\mathrm{it}$ & $\mathrm{se}$ & $\mathrm{uk}$ \\
\hline Real Estate & 1.31 & 0.77 & 0.32 & 0.78 & 1.37 & 2.12 & 0.48 & 2.75 & 1.09 \\
Wood & 0.96 & 1.05 & 1.10 & 0.98 & 2.62 & 0.68 & 1.38 & 1.84 & 0.51 \\
Leather & 0.50 & 0.24 & 0.27 & 1.18 & 0.67 & 0.77 & 3.54 & 0.14 & 0.45 \\
Construction & 9.15 & 0.87 & 1.17 & 1.28 & 0.76 & 1.14 & 0.99 & 1.00 & 0.90 \\
Textile & 2.43 & 0.54 & 0.62 & 0.97 & 0.64 & 0.79 & 2.30 & 0.27 & 0.84 \\
Hotel\&Rest. & 5.61 & 0.74 & 0.89 & 1.46 & 0.64 & 0.84 & 1.07 & 0.60 & 1.22 \\
Other Serv. & 3.71 & 1.04 & 0.53 & 1.06 & 0.69 & 0.89 & 0.93 & 0.61 & 1.23 \\
Business Services & 11.13 & 1.10 & 0.95 & 0.95 & 0.75 & 1.07 & 0.71 & 0.96 & 1.23 \\
Pap.\&Pub. & 2.28 & 0.93 & 1.85 & 0.77 & 3.19 & 0.94 & 0.87 & 2.12 & 1.23 \\
Metal Prod. & 3.70 & 1.11 & 0.99 & 0.86 & 1.17 & 0.98 & 1.47 & 1.23 & 0.80 \\
Non-met. Prod. & 1.25 & 0.96 & 1.04 & 1.28 & 1.07 & 0.86 & 1.50 & 0.70 & 0.67 \\
Food & 3.51 & 0.94 & 1.79 & 1.17 & 1.32 & 1.17 & 0.98 & 0.90 & 0.70 \\
Trade & 21.20 & 0.77 & 1.26 & 1.21 & 0.88 & 0.94 & 1.15 & 0.97 & 1.00 \\
Transport & 1.35 & 1.06 & 0.85 & 0.84 & 1.30 & 0.98 & 1.01 & 1.25 & 1.10 \\
Rubber & 1.20 & 1.15 & 1.13 & 0.80 & 1.02 & 1.13 & 1.09 & 0.92 & 1.00 \\
Machinery & 2.88 & 1.26 & 1.72 & 0.56 & 1.61 & 0.85 & 1.39 & 1.779 & 0.83 \\
Other Manuf. & 2.33 & 2.01 & 1.02 & 0.70 & 0.57 & 0.60 & 1.00 & 0.45 & 0.49 \\
Chemical & 1.74 & 1.19 & 0.97 & 0.83 & 1.02 & 1.11 & 0.95 & 0.87 & 0.84 \\
Elett. Mach. & 3.60 & 1.84 & 0.77 & 0.43 & 1.01 & 0.83 & 0.90 & 0.98 & 0.68 \\
Finance & 4.30 & 1.01 & 1.23 & 0.95 & 1.24 & 0.97 & & 0.94 & 1.16 \\
Petroleum & 0.17 & 0.77 & 0.07 & 0.55 & 2.74 & 1.36 & 1.14 & 0.69 & 1.32 \\
Transp. Equip. & 2.32 & 1.27 & 0.67 & 0.83 & 0.79 & 1.23 & 0.97 & 1.67 & 0.90 \\
\hline
\end{tabular}

share of employment in sector $i$ in country $j$, and barred variables are the corresponding values for the benchmark. The first term, $\Delta_{\omega}$, represents the difference due to differences in the sectoral composition of employment and the second, $\Delta_{s}$, the differences due to the size differences within sectors and $\Delta_{\omega s}$ an iteraction term. If the latter is positive, size and sectoral composition deviate from the benchmark in the same direction. Results from the decomposition are reported in Table 4.

For all countries, the interaction term is positive, indicating that size and sectoral deviations tend to go togheter, confirming our previous result. Denmark and France are very close to the reference, Germany and the UK well above, and Spain and Italy below it. In terms of relative weights, the differences in size within sectors tend to be higher than those coming from sectoral specialization. 
Table 3: OLS regression of sectoral share on an index of EU15 size

\begin{tabular}{lcccccccc}
\hline \hline & $\mathrm{de}$ & $\mathrm{dk}$ & $\mathrm{es}$ & $\mathrm{fi}$ & $\mathrm{fr}$ & $\mathrm{it}$ & $\mathrm{se}$ & $\mathrm{uk}$ \\
\hline Size & .225 & .031 & -.152 & .061 & -.018 & -.295 & -.083 & .050 \\
& $(.088)$ & $(.123)$ & $(.061)$ & $(.193)$ & $(.082)$ & $(.166)$ & $(.166)$ & .070 \\
Constant & -.276 & .782 & 1.807 & .876 & 1.115 & 2.890 & 1.558 & .629 \\
& $(.512)$ & $(.718)$ & $(.354)$ & $(1.127)$ & $(.482)$ & $(.970)$ & $(.971)$ & $(.407)$ \\
$R^{2}$ & .25 & .003 & .24 & .01 & 0 & .14 & .01 & .03 \\
\hline
\end{tabular}

Table 4: Contribution to size difference: sectoral specialization and average size

\begin{tabular}{lcccc}
\hline \hline Ctry & $\Delta_{\omega} / \bar{s}$ & $\Delta_{s} / \bar{s}$ & $\Delta_{\omega s} / \bar{s}$ & $\left(s_{j-} \bar{s}\right) / \bar{s}$ \\
\hline de & .10 & .39 & .09 & .58 \\
dk & .07 & -.20 & .10 & -.03 \\
es & -.06 & -.39 & .03 & -.42 \\
fi & .02 & -.07 & .11 & .06 \\
fr & -.01 & -.03 & .02 & -.02 \\
it & -.08 & -.59 & .09 & -.58 \\
se & .06 & .04 & .03 & .13 \\
uk & -.03 & .57 & .04 & .58 \\
\hline
\end{tabular}

Note: $\left(s_{j-} \bar{s}\right) / \bar{s}$ is the deviation of overall mean size from the reference, $\Delta_{\omega} / \bar{s}$ the deviation due to sectoral specialization, $\Delta_{s} / \bar{s}$ the deviation due to smaller size within sector and $\Delta_{\omega s} / \bar{s}$ the deviation due to the interaction term 
Summing up, from this analysis we draw two conclusions that form the basis for our econometric work:

1. there are sizeable differences in size distribution for the same sector across countries, which gives enough variability in the covariates for the econometric analysis of the next section;

2. at the country level, average size within sector and sectoral specialization pattern move in the same direction, an indication that acrosscountries size comparisons can safely be made.

\section{Size Structure and Growth}

In this section we examine the relationship between growth and firm size structure. Growth theories have long attributed to technological advances the role of engine of the process. In the literature spurred in the nineties by the contributions of Romer (1990) and Grossman and Helpman (1991), technological progress has been endogenized and the incentives to undertake research and development have become the crucial factors in determining growth. Yet, the role of the structure of the market has been neglected. For example, in Romer's model (1990), firms producing the final goods rent technological advances (in the form of different intermediate capital inputs) from the intermediate capital goods sector. Given that returns to scale in the final good sector are constant, there is no role for firm size. In reality, part of the $\mathrm{R} \& \mathrm{D}$ is done within the same firms producing the final goods, which use the advances within the firm rather than renting out intermediate goods produced with such advances to other firms. In this case, the size of a firm will generally have an influence on the incentives to undertake R\&D. Consider for example a cost-reducing innovation. For given firm's output and prices, the benefits of a given reduction in costs are larger the larger the scale of production. If the $R \& D$ expenditure has a fixed-cost character, then a larger firm will benefit more from investing in it.

In a series of papers Peretto $(1998,1999 a, 1999 b)$ recognizes the simultaneity between R\&D decisions - and thus economic growth - and market structure, pointing out the twofold aspect of this relationship: from one hand market structure determines the behavior of profit-seeking firms by affecting the returns to investment (and thus growth), from the other hand market structure changes in response to growth, insofar as the number and the size of existing firms changes in response to demand and technological conditions. Peretto identifies two effects of market structure on growth: from one 
hand increasing returns in $\mathrm{R} \& \mathrm{D}$, internal to the firms, imply that the more concentrated are resources the higher growth (dispersion effect). Yet from the other hand, the full effect of market structure on growth depends also the increase of competition on aggregate $\mathrm{R} \& \mathrm{D}$ (rivalry effect). In sum, in these papers, an increase in the number of firms has a twofold outcome for growth: (i) holding constant aggregate $\mathrm{R} \& \mathrm{D}$, it reduces average $\mathrm{R} \& \mathrm{D}$ and, therefore, reduces growth (dispersion effect); (ii) it raises aggregate R\&D and, thus, raises growth (rivalry effect). ${ }^{9}$

To investigate the relationship between size structure and growth, we integrate the data of the previous section with data on value added at the sectoral level. Because of data availability, we restrict the analysis to the manufacturing sector. Where possible, we use the most disaggregated sectoral classification, that is the two digits Nace rev. 1. For most countries, we are also constrained to use data referring to enterprises employing 20 persons or more, yet we think that it is not a fundamental limitation since we will argue that all our results carry through when we use alternative measures of firm size that neglect the left tail of the distribution. Other details of the data construction are given in Appendix 2.

The framework that we use is standard in the literature on growth (Barro and Sala-i-Martin, 1995). It relates the real per capita growth rate to two kinds of variables, a set of control variables - initial level of real per capita GDP and proxies for the level of physical and human capital - and a set of variable of interests, in our case measures of firm size distribution.

As mentioned above, this type of regressions might suffer from endogeneity problems. In fact, it could be argued that the correlation between growth and firm size masks a causality running also (or exclusively) from the former to the latter. ${ }^{10}$ We address this issue in the following way. First, in our regressions we take the average growth rate for the period after the year in which the size distribution refers to. Given that the size structure data refer to 1994, we consider growth as the compounded percentage change in real value added per worker between 1994 and 1998. The fact that we consider a relatively short time span could induce some bias in terms of the

\footnotetext{
${ }^{9}$ Note that in these papers the number of firms summarize two dimensions of the notion of market structure - concentration and firm size relative to the size of the market. In our empirical investigation we will study the relationship between size structure and growth, neglecting issues related to market power. Clearly, firm size and market power are correlated. Still, given that other issues that we cannot address with our data are important for market power, we confine ourselves to size structure.

${ }^{10}$ For instance, in Lucas (1978) as capital per capita grows, the "marginal" entrepeneur finds profitable to become an employee, thereby causing an increase in the average firm size.
} 
relative cyclical position of the various countries. This problem is mitigated by the fact that we only consider countries of the European Union, whose business cycles have been fairly synchronized, with the notable exception of the UK. We will show that our results are not driven by any particular country and that they hold true also when we use a growth rate calculated over the between 1989-1998 period. Still, this restriction on the data could not be enough to avoid endogeneity problems, particularly when the variables involved are characterized by a high level of persistence. ${ }^{11}$ Therefore, in addition, and more decisively, in the next section we will run a direct test of reverse causation.

The basic regression we run is the following:

$$
g_{i, j}=\alpha_{0}+\boldsymbol{\alpha}_{1}{ }^{\prime} X_{i, j}+\alpha_{2} \ln \left(S_{i, j}\right)+\lambda_{i}+\varepsilon_{i, j}
$$

where $g$ is the average growth rate of real value added per worker in country $j$ in sector $i ; X$ is a vector of control variables; $S$ is log of 1 plus the average firm size (co-worker mean) in country $j$ in sector $i$ in $1994 ; \lambda_{i}^{\prime}$ s are sectoral dummies and $\varepsilon$ is an error term.

The dependent variable is the average annual growth rate of value added per worker, whose descriptive statistics are given in tables 12 and 13. All our regressions include sectoral dummies, so that we net out the average growth rate at the sectoral level: our estimates will relate each sector's own growth in deviation from the average sectoral growth rate across countries to size, again in deviation from the cross-countries mean. This ensures that our results are not driven by the particular growth performance of any sector over the sample period. Moreover, given that, as shown in the previous section, the countries in our sample are characterized by systematic size differences, we run our basic specification without country dummies, which might pick up a large part of the size effect we are trying to capture. We always report heteroskedasticity corrected standard errors.

The results of the basic regressions are reported in Table 5. The first column anticipates a result that will hold through all our analyses: the average firm size is positively correlated with growth in value added per worker. The coefficient of the average size is in fact positive, with a value of .018 , and significant, with a t-statistic of 2.9. To give a crude appreciation of this result, this number implies that, ceteris paribus, if average firm size rises by $10 \%$, the growth rate of value added per capita would increase roughly

\footnotetext{
${ }^{11}$ A study based on the comparison of the major industrialized economies from the mid sixties to the mid nineties show that the size structures display a high level of persistence, and that the structures across countries show little evidence of convergence (Traù, 1999).
} 
Table 5: Growth and average firm size

\begin{tabular}{lccccccc}
\hline \hline & {$[1]$} & {$[2]$} & {$[3]$} & {$[4]$} & {$[5]$} & {$[6]$} & {$[7]$} \\
\hline$y_{0}$ & -.038 & -.042 & -.036 & -.0423 & -.031 & -.036 & -.025 \\
& $(.018)$ & $(.023)$ & $(.023)$ & $(.018)$ & $(.018)$ & $(.018)$ & $(.026)$ \\
$\bar{\imath}$ & & .005 & .008 & & & & \\
& & $(.016)$ & $(.016)$ & & & & \\
$h$ & & & -.018 & & & & \\
& & & $(.017)$ & & & & \\
$s$ & .018 & .018 & .019 & .014 & .0093 & .096 & .009 \\
& $(.006)$ & $(.006)$ & $(.006)$ & $(.007)$ & $(.0063)$ & $(.033)$ & $(.007)$ \\
$v$ & & & & -.0196 & & & \\
& & & & $(.0137)$ & & & \\
\hline Number of obs. & 136 & 136 & 136 & 136 & 138 & 136 & 136 \\
$\mathrm{~F}$ [p-value] & .0040 & .0060 & .0022 & .0016 & .0398 & .0120 & .0000 \\
$R^{2}$ & .2698 & .2705 & .2770 & .2820 & .2215 & .2626 & .4654 \\
\hline
\end{tabular}

Notes: OLS estimates, heteroskedasticity robust standard error in parentheses; dependent variable is the compounded percentage change in real value added per worker between 1994 and $1998 ; y_{0}$ is the logarithm of real value added per worker at the beginning of the period; $\bar{i}$ is the logarithm of average investment rate in the period; $h_{0}$ is the logarithm of an index of human capital and $s$ is the logarithm of average firm size and $v$ the logarithm of the variance, both in 1994. Firm size is defined as the co-worker mean (see text) in all columns but in [5] where it is the arithmetic mean and in [6] where it is proxied by the share of employment in large firms. All regressions include a full set of sectoral dummies, column [7] includes also a full set of country dummies.

by .18 percentage point per year. This result might seem in contrast with the conventional wisdom that small firms are the most dynamic component of an industry and grow faster than large firms. Yet, this is not the case for two reasons. First, it has been shown that small (young) firms grow fast conditional on surviving, and that exit rates are much higher among them (Dunne et al., 1989). Once this is taken into account, results change drastically. For example, Davis et al. (1996) find a marginal role of small firms in term of job creation and destruction for the US economy. Second, we are not interested in individual growth rates for different size classes, but in the effect of a given steady-state size distribution on productivity growth at the sectoral level. In this respect, we find that a larger average firm size is associated with higher productivity growth. 
The other columns of Table 5 expand the basic specification and perform robustness checks. Labor productivity depends on the capital/labor ratio and therefore one needs to control for changes in investment rates when explaining changes in productivity. The positive correlation between average firm size and productivity growth might be due to our definition of firm size spuriously capturing the effect of capital intensity on growth. Yet the result of column 1 holds true even when we further control for country/sector differences in investment rates - a proxy for the capital intensity — (column [2]) and also for country differences in human capital (column [3]), indicating that the effect of average firm size on growth goes "above and beyond its effects on the incentives to invest" (Sala-i-Martin, 1997) ${ }^{12}$. The coefficient on initial real value added per worker is always negative and significant, indicating that on average there is evidence of convergence across countries (within sectors) ${ }^{13}$.

Eeckhout and Jovanovic (1998) study the relationship between the characteristics of the technological process, the size distribution of firms and the steady-state investment and growth. They consider firms ranking in terms of capital, and show that the dispersion in size can have positive or negative effects on growth according to the "free-riding" or the "rent-grabbing" nature of technological progress. When returns from investments are appropriable, a firm has a high incentive to invest in order to improve its ranking in the size distribution; if the distribution is very disperse, however, the cost of improving one's rank are higher than if the distribution is concentrated, so inequality has a negative impact on growth. ${ }^{14}$ In the free-riding case, each firm can benefit from the spillovers from firms that are higher in the ranking. Given that an increase in one's ranking position decreases access to usable knowledge of others, the prospect of increasing the ranking is a deterrent to investment. In this case, the more disperse the distribution the lower the increase in the ranking coming from investment. Therefore, dispersion reduces the negative component of return to investment coming from external economies, so that it is good for investment incentives and for

\footnotetext{
${ }^{12}$ We have also experimented with the measures of human capital recently constructed by De la Fuente and Domenech (2000), with similar results.

${ }^{13}$ Bernard and Jones (1996) find that value added per worker in manufacturing does not exhibit convergence in a sample of OECD countries after 1975. This finding is not directly comparable with our result since we do not weight sectors with their own share in manufacturing and therefore the coefficient of $y_{0}$ cannot be used to recover the speed of convergence of value added per worker in total manufacturing across countries.

${ }^{14} \mathrm{~A}$ similar result is obtained in a class of models that study the incentives to develop a multi-stage patent: when competitors are close to each other, the rate of investment in R\&D is higher (Budd, Harris and Vickers, 1993).
} 
growth.

To investigate this issue, we need a measure of size dispersion. Unfortunately, our dataset only allows to compute dispersion across classes, while we have no inofrmation on that between classes, which is likely to be the most relevant component of overall dispersion. As a measure of dispersion, we use the (negative of the) standard deviation of sectoral employment across classes. When employment is concentrated in one class, size dispersion is minimum (and standard deviation maximum), and the reverse is true when it is equally distributed across classes. Column (4) reports the results for the basic regression with the addition of the dispersion measure. We find suggestive evidence of a negative effect of dispersion on growth: the coefficient on the variance is negative but imprecisely estimated (the p-value is .15). Similar indications emerge when we use alternative measures of dispersion. We conclude that this aspect deserves further investigation, based on a more precise measure of variability than the one available in our dataset.

The last three columns of Table 5 control for the robustness of our measure of size. The first column uses a simple arithmetic mean, defined as total employment divided by the total number of firms in the sector. This measure gives a higher weight to small firms than the co-worker mean. The coefficient is still positive but statistically not significant. In column 6 , to deal with the problem of potential measurement error coming from the fact that different countries define the firm in different ways mentioned in the preceding section, we proxied average firm size with the share of employment in large firms (i.e. that in the last size class). This measure delivers a positive and highly significant coefficient. Finally, in column 7 we also include country dummies using the basic measure of size as in column 1 . The coefficient of average size becomes smaller and it is statistically not significant, a further confirmation of the fact that large parte of the size variability comes from country-level differences.

As a further robustness check, in order to prove that our results are not driven by any particular country of the sample selected, we have reestimated our basic specification given in column 1 in Table 5 for each possible subsample by deleting one country at time. Figures 1 displays the estimated coefficient of average firm size and the 95 per cent confidence interval around it. To facilitate comparison with the baseline, the dotted line represent the coefficients estimates with the full sample. As is evident from the figures, sample composition does not affect significantly estimated coefficients.

We finally investigate the possibility that our results are distorted by the relatively short time span over which we calculate growth rates. Table 6 


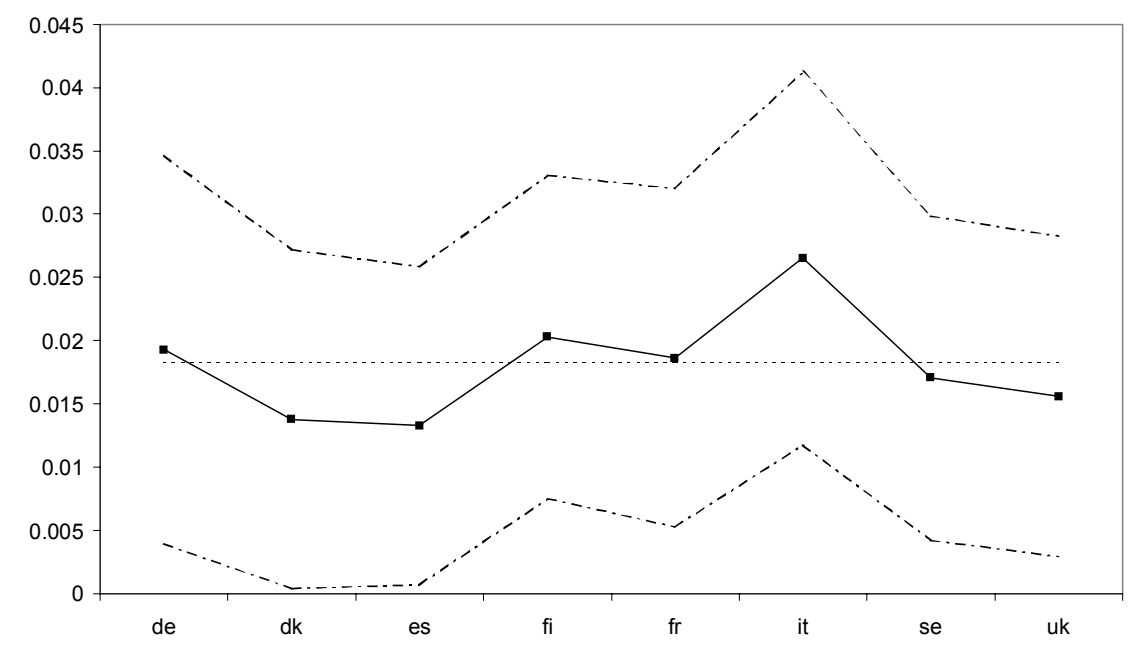

Figure 1: Robustness of $\alpha_{2}$ to country deletion

Note: point estimate and 95\% confidence intervals of $\alpha_{2}$ (specification [1] in table 5 ) after excluding the country shown on the horizontal axis. The dotted line is the coefficient estimate with the whole sample.

replicates exactly the same regressions as the previous one, using as dependent variable the growth rate of labor productivity over the entire decade. Indeed, our estimates, particularly those of the size coefficient, are very stable with respect to this modification. The main differences between the two tables are that here the coefficients tend to be more precisely estimated. The dispersion measure is now significant at $10 \%$. Moreover, we obtain a significant correlation between size and productivity growth also when we use the arithmetic mean as an indicator of sectoral size, a further element supporting the robustness of the positive correlation between average firm size and productivity growth.

\section{A causality test through $R \& D$ intensity}

Our regressions are not immune from the criticism that plagues most of the empirical growth literature, related to establishing the direction of causality (the so-called post hoc, ergo propter hoc problem). This problem originates from the fact that (i) both the dependent and the explanatory variables 
Table 6: Growth and average firm size: longer time span

\begin{tabular}{lccccccc}
\hline \hline & {$[1]$} & {$[2]$} & {$[3]$} & {$[4]$} & {$[5]$} & {$[6]$} & {$[7]$} \\
\hline$y_{0}$ & -.059 & -.067 & -.069 & -.061 & -.060 & -.059 & -.028 \\
& $(.008)$ & $(.008)$ & $(.009)$ & $(.008)$ & $(.009)$ & $(.008)$ & $(.014)$ \\
$\bar{\imath}$ & & .025 & .025 & & & & \\
& & $(.009)$ & $(.009)$ & & & & \\
$h$ & & & .007 & & & & \\
& & & $(.010)$ & & & & \\
$s$ & .014 & .013 & .012 & .011 & .013 & .070 & .004 \\
& $(.003)$ & $(.003)$ & $(.003)$ & $(.004)$ & $(.003)$ & $(.017)$ & $(.004)$ \\
$v$ & & & & -.0137 & & & \\
& & & & $(.0078)$ & & & \\
\hline Number of obs. & 136 & 136 & 136 & 136 & 137 & 136 & 136 \\
$\mathrm{~F}$ [p-value] & .0000 & .0000 & .0000 & .0000 & .0000 & .0000 & .0000 \\
$R^{2}$ & .5516 & .5830 & .5852 & .5634 & .5241 & .5330 & .7181 \\
\hline
\end{tabular}

Notes: OLS estimates, heteroskedasticity robust standard error in parentheses; dependent variable is the compounded percentage change in real value added per worker between 1989 and 1998; $y_{0}$ is the logarithm of real value added per worker at the beginning of the period; $\bar{i}$ is the logarithm of average investment rate in the period; $h_{0}$ is the logarithm of an index of human capital and $s$ is the logarithm of average firm size and $v$ the logarithm of the variance, both in 1994. Firm size is defined as the co-worker mean (see text) in all columns but in [5] where it is the arithmetic mean and in [6] where it is proxied by the share of employment in large firms. All regressions include a full set of sectoral dummies, column [7] includes also a full set of country dummies.

could be driven by a common omitted variable and/or (ii) the explanatory variable may simply be a leading indicator — and not a causal factor of economic growth. ${ }^{15}$ We tackle the problem of reverse causality following an idea of Rajan and Zingales (1998). The basic insight consists in defining some sectoral characteristics that allow us to rank the sectors in terms of the relative importance of size for growth. This characteristic should have two features: first, it should potentially constitute a channel trough which

\footnotetext{
${ }^{15}$ For example, if the direction of casality goes from high growth to larger firm size, and if the growth rate is highly persistent, then the positive correlation between average size in 1994 and growth rate after that year could be due to the fact that high growth sectors in the period we consider were also growing fast before, thus inducing the ex-post correlation we find.
} 
size influences growth, and second, it should display a certain degree of sectoral variability. If we find that size has a differential effect on growth in accordance with such characteristic, we can conclude that our results cannot be generated by some general form of spurious correlation, like the one induced by reverse causality, which should deliver an homogeneous relation between size and growth. Moreover, this also means that the effect of size on growth does take place through this channel.

Following a suggestion coming from the endogenous growth literature, we select R\&D intensity as the candidate channel to explain the relationship between firm size and growth. Sector with larger firms could engage in more $R \& D$ and therefore experience a higher growth of productivity. The possibility that large firms might undertake more $R \& D$ was recognized already by Schumpeter (1934). The fixed cost character of many R\&D projects implies that they are profitable only if their results can be applied to sufficiently large productions, generating higher incentives to invest in R\&D. In addition, $\mathrm{R} \& \mathrm{D}$ activity might itself be characterized by economies of scale and scope: once an innovation has been developed, large and diversified firms might have better opportunities to exploit it. Finally, large firms should have a better capacity to finance R\&D expenditure, both through a larger internal cash flow and through a better access to external sources of funding. In terms of sectoral variability, not all sectors are characterized by the same patterns of technological change and, as a consequence, of equilibrium $R \& D$ intensity, as noted, among others, by Pavitt (1984)..

If we think that, ceteris paribus, the propensity to undertake investment in $\mathrm{R} \& \mathrm{D}$ increases more than proportionally with size ${ }^{16}$ or that an innovation might be better exploited by large firms, then one should expect that size differences are more relevant for growth in R\&D intensive sectors. For example, if the Textile sector undertakes relatively little investment in R\&D, then we should expect that size differences are not a major source of differences in growth rates. By the same token, an industry structure with a predominance of small size in Chemicals, typically R\&D intensive, should have a much stronger negative influence on growth.

To implement this intuition, we need a classification of R\&D intensity

\footnotetext{
${ }^{16}$ There exist an extensive empirical literature studing the relationship between size and propensity to invest in innovative activities at the firm level (see Symeonidis (1996) for a survey). Results from this literature are not conclusive, also due to the problems related to the measurement of innovative activity, the endogeneity of the firm size and industry effects. A fairly robust finding is that small firms generally do not engage in $\mathrm{R} \& \mathrm{D}$, lending some indirect support to the view that a smaller average size would lead to a lower aggregate $R \& D$.
} 
Table 7: Average share of R\&D in the US

\begin{tabular}{lccc}
\hline \hline sectors & $\frac{R \& D \text { Pers. }}{\text { Empl. }}$ & $\frac{R \& D \text { Exp. }}{\text { Inv. }}$ & $\frac{R \& D \text { Exp. }}{\text { V.A. }}$ \\
\hline Food\&Bev. (15) & .59 & 12.29 & 1.17 \\
Textile (17) & .29 & 8.26 & .60 \\
Wearing App. (18) & .11 & 8.26 & .60 \\
Leather (19) & .29 & 8.26 & .60 \\
Wood (20) & .09 & 8.29 & 2.66 \\
Paper (21) & 1.69 & 9.41 & 1.11 \\
Publishing (22) & .24 & 9.41 & 1.11 \\
Chemicals (24) & 9.67 & 63.56 & 9.70 \\
Rubber (25) & .91 & 23.46 & 3.17 \\
Non metallic prod. (26) & .84 & 19.71 & 2.04 \\
Basic Metals (27) & 1.11 & 11.03 & 1.51 \\
Fabric. Metal Prod.(28) & .71 & 24.46 & 1.41 \\
Machinery and Comp. (29+30) & 3.33 & 142.97 & 12.27 \\
Electrical machinery (31) & 3.21 & 105.93 & 7.10 \\
Communic. Equipment (32) & 11.45 & 133.64 & 17.27 \\
Precision Instruments (33) & 11.90 & 204.85 & 18.70 \\
Motor Vehicles (34) & 5.38 & 120.37 & 20.10 \\
Other Transp.Equip. (35) & 8.68 & 211.89 & 25.42 \\
\hline
\end{tabular}

external to our data set. We will use different indicators of $R \& D$ intensity at the sectoral level for the US economy. The US constitute a natural benchmark to determine the R\&D propensity of sectors in an unconstrained environment, given the relatively low level of regulation and the high development of the financial sector, which should minimize the problems of R\&D financing. Given the well known problems associated with defining and measuring $R \& D$ activity, we will use three different indicators to assess the robustness of our findings: share of people employed in R\&D activity, $R \& D$ expenditure over investment and $R \& D$ expenditure over value added. The values are reported in Table 7, and details of the construction of our variables and of data sources are in Appendix 2.

For all indicators, the sectoral rankings in Table 7 are as expected: the least $\mathrm{R} \& \mathrm{D}$ intensive sectors are the traditional ones, such as Textile, Leather and Wood, while at the top of the ranking we find the "high tech" sectors, such as Communication Equipments and Precision Instruments. Indeed, even if we cannot match directly the classification of Pavitt (1984) because of 
differences in the sectorial subdivision, a clear pattern emerge from the table, which places at the bottom of intensity the "supplier dominated sectors", in the medium range the "production intensive sectors" and at the top the "science-based sectors". The range of variation is higher for the indicator based on the share of personal in $\mathrm{R} \& \mathrm{D}$ activity, characterized by a ratio of the least intensive (Wood) to the most intensive (Precision Instruments) of 132, compared to 25 for R\&D/Investment (Wearing Apparel vs. Other Transportation Equipment) and 42 for the R\&D/Value Added (Textile vs. Communication Equipments). The rankings are very similar across the three indicators, the main exceptions being Wearing Apparel which has a higher ranking according the $\mathrm{R} \& \mathrm{D} /$ Value Added indicator and Chemicals, placed higher in the ranking by the share of personal indicator. The coefficient of correlation is always high and, as should be expected, maximum for the last two indicators (.95), while is minimum for the first two (.83).

The first test we design to tackle the issue of reverse causality is based on a split of sectors according to the ranking of the US sectors by the three indicators of R\&D intensity just selected. For each indicator, we construct a dummy variable that takes on the value 1 for those sectors that are above a certain value (usually the median) in the distribution of US sectors by R\&D intensity and 0 for those sectors that are below. We then split the sectors of our sample according to this dummy with the idea that the group of sectors characterized by a relatively higher R\&D intensity should display a relatively higher impact of size on growth. We also do the same splitting the distribution of US sectors by R\&D intensity in three sub-samples ${ }^{17}$.

Table 8 present the results for a regression similar to (7) in which the size coefficient is allowed to vary between groups. All the regressions give the same result, namely the higher ranked are sectors according to the various R\&D intensity indicators in the US, the higher is the effect of average firm size on growth. Moreover, for the very low $R \& D$ intensive sectors (columns 2, 4 and 6) we can never reject the hypothesis that the correlation between firm size and growth is nil.

A more "formal" test of reverse causality is based on the estimation of equation (7) augmented as follows:

$$
g_{i, j}=\theta_{0}+\boldsymbol{\theta}_{1}^{\prime} X+\theta_{2} \ln \left(S_{i, j}\right)+\theta_{3}\left[\ln \left(S_{i, j}\right) \times D_{i}\right]+\lambda_{i}+\epsilon_{i, j} .
$$

$D$ is the variable that captures the differential sectoral effect of firm size on growth, that is R\&D intensity. If our sectoral classification is correct, and if

\footnotetext{
${ }^{17}$ For further details see Appendix 2.
} 
Table 8: R\&D split

\begin{tabular}{|c|c|c|c|c|c|c|}
\hline $\mathrm{R} \& \mathrm{D}$ as $\rightarrow$ & $\% \mathrm{pe}$ & onnel & $\%$ inv & stment & $\%$ valu & added \\
\hline variables $\downarrow$ & [1] & [2] & [3] & [4] & [5] & [6] \\
\hline$y_{0}$ & -.0410 & -.0401 & -.0381 & $\begin{array}{l}-.0379 \\
\end{array}$ & -.0380 & $\begin{array}{l}.0388 \\
\end{array}$ \\
\hline & $(.0179)$ & $(.0181)$ & $(.0180)$ & $(.0182)$ & $(.0181)$ & $(.0180)$ \\
\hline$s_{h i g h}$ & .0288 & .0263 & .0222 & .0261 & .0262 & .0264 \\
\hline & $(.0090)$ & $(.0098)$ & $(.0092)$ & $(.0099)$ & (.0098) & $(.0129)$ \\
\hline$s_{\text {med }}$ & & .0215 & & .0202 & & .0162 \\
\hline & & $(.0140)$ & & $(.0136)$ & & $(.0061)$ \\
\hline$s_{\text {low }}$ & .0092 & .0087 & .0145 & .0098 & .0133 & .0143 \\
\hline & $(.0074)$ & $(.0082)$ & $(.0080)$ & $(.0088)$ & $(.0076)$ & $(.0103)$ \\
\hline Number of obs. & 136 & 136 & 136 & 136 & 136 & 136 \\
\hline $\mathrm{F}$ [p-value] & .0004 & .0009 & .0023 & .0009 & .0014 & .0039 \\
\hline$R^{2}$ & .2900 & .2831 & .2729 & .2813 & .2782 & .2755 \\
\hline
\end{tabular}

Notes: OLS estimates, heteroskedasticity robust standard error in parentheses; dependent variable is the compounded percentage change in real value added per worker between 1994 and 1998; splits are according to the share of personnel employed in R\&D in total employment in columns [1]-[2], the ratio of total expenditure in research and development and total fixed capital formation in columns [3]-[4], and the ratio of total expenditure in research and development and value added in columns [5]-[6], all in the US. For further details see Appendix 2. All regressions include a full set of sectoral dummies.

the direction of causality goes from size to growth, the coefficient $\theta_{3}$ should be positive and significant. Notice that if the assumption that the effect of size on growth takes place through $D$ is confirmed, we should observe a decline in the estimate of the overall correlation of the effect between firm size and growth, captured by $\theta_{2}$. If $D$ is the only channel, only the interaction term should matter and the estimate of $\theta_{2}$ should become close to zero.

Table 9 reports the results of the regressions. For any indicatory of R\&D intensity used, the point estimate of the coefficient of firm size $(s)$ is lower than the corresponding estimate without the interaction term - given in column 1 of table 5 - and, more importantly, it is always statistically not significant at conventional levels. The coefficient on the interaction term $s \times R \& D_{U S}$ is always positive, and significant at 10 per cent when the indicator is the share of $R \& D$ personnel in total employment. When we drop the measure of average firm size (not interacted), the interaction is 
Table 9: R\&D interaction

\begin{tabular}{lcccccc}
\hline \hline R\&D as $\rightarrow$ & \multicolumn{2}{c}{ \% personnel } & \multicolumn{2}{c}{ \% investment } & \multicolumn{2}{c}{ \% value added } \\
\hline variables $\downarrow$ & {$[1]$} & {$[2]$} & {$[3]$} & {$[4]$} & {$[5]$} & {$[6]$} \\
\hline$y_{0}$ & -.0378 & -.0328 & -.0382 & -.0335 & -.0387 & -.0333 \\
& $(.0180)$ & $(.0177)$ & $(.0181)$ & $(.0178)$ & $(.0180)$ & $(.0179)$ \\
$s$ & .0098 & & .0104 & & .0127 & \\
& $(.0073)$ & & $(.0080)$ & & $(.0081)$ & \\
$s \times R \& D_{U S}$ & .00269 & .00387 & .00013 & .00021 & .00078 & .00154 \\
& $(.00145)$ & $(.00114)$ & $(.00009)$ & $(.00007)$ & $(.00087)$ & $(.00066)$ \\
\hline Number of obs. & 136 & 136 & 136 & 136 & 136 & 136 \\
$\mathrm{~F}[\mathrm{p}$-value $]$ & .0004 & .0002 & .0007 & .0003 & .0023 & .0017 \\
$R^{2}$ & .2933 & .2813 & .2857 & .2736 & .2780 & .2594 \\
\hline
\end{tabular}

Notes: OLS estimates, heteroskedasticity robust standard error in parentheses; dependent variable is the compounded percentage change in real value added per worker between 1994 and 1998; $y_{0}$ is the logarithm of real value added per worker in 1994; $s$ is the logarithm of average firm size in 1994; $R \& D$ is the share of personnel employed in $\mathrm{R} \& \mathrm{D}$ in total employment in columns [1]-[2], the ratio of total expenditure in research and development and total fixed capital formation in columns [3]-[4], and the ratio of total expenditure in research and development and value added in columns [5]-[6], all in the US. All regressions include a full set of sectoral dummies.

always significant. Our interpretation of the positive relationship between growth and this interaction term is that the influence of average firm size on growth is larger for sectors with an "intrinsically" high expenditure in R\&D. In other words, the fact that the relationship between firm size and growth varies with an external sectoral ranking - namely R\&D intensity in the US - leads us to conclude that the positive correlation we find is not generated by reverse causality.

The regressions of table 9 control for sectoral effects but not for country effects. A possible objection to our findings is that the positive value of the coefficient on the interaction term might be due to omitted variables, varying across countries. Indeed the interaction term introduces a new source of within country variability that should not by wiped out by country dummies. Therefore, to limit the bias coming from the omission of potential explanatory variables at country level, we inserted in equation (8) also a full set of country dummies. This amounts to restrict ourselves to a within 
Table 10: R\&D interaction: controlling also for country effects

\begin{tabular}{lcccccc}
\hline \hline R\&D as $\rightarrow$ & \multicolumn{2}{c}{$\%$ personnel } & \multicolumn{2}{c}{ \% investment } & \multicolumn{2}{c}{ \% value added } \\
\hline variables $\downarrow$ & {$[1]$} & {$[2]$} & {$[3]$} & {$[4]$} & {$[5]$} & {$[6]$} \\
\hline$y_{0}$ & -.0206 & -.0210 & -.0247 & -.0245 & -.0268 & -.0257 \\
& $(.0269)$ & $(.0240)$ & $(.0266)$ & $(.0242)$ & $(.0261)$ & $(.0243)$ \\
$s$ & -.0005 & & .0003 & & .0019 & \\
& $(.0082)$ & & $(.0087)$ & & $(.0090)$ & \\
$s \times R \& D_{U S}$ & .00300 & .00296 & .00015 & .00015 & .00095 & .00105 \\
& $(.00128)$ & $(.00103)$ & $(.00008)$ & $(.00006)$ & $(.00075)$ & $(.00059)$ \\
\hline Number of obs. & 136 & 136 & 136 & 136 & 136 & 136 \\
$\mathrm{~F}[\mathrm{p}$-value] & .0000 & .0000 & .0000 & .0000 & .0000 & .0000 \\
$R^{2}$ & .4923 & .4923 & .4835 & .4835 & .4762 & .4759 \\
\hline
\end{tabular}

Notes: OLS estimates, heteroskedasticity robust standard error in parentheses; dependent variable is the compounded percentage change in real value added per worker between 1994 and 1998; $y_{0}$ is the logarithm of real value added per worker in $1994 ; s$ is the logarithm of average firm size in $1994 ; R \& D$ is the share of personnel employed in R\&D in total employment in columns [1]-[2], the ratio of total expenditure in research and development and total fixed capital formation in columns [3]-[4], and the ratio of total expenditure in research and development and value added in columns [5]-[6], all in the US. All regressions include a full set of sectoral and country dummies.

country prediction: that is the coefficient on the interaction term will now tell us whether in each country industries that are more R\&D intensive grow more the higher firm size ${ }^{18}$.

The results, presented in table 10, are striking. The coefficient on firm size alone is always literally nil, as expected from the result in column 7 in table 5. On the contrary, the interaction term is positive and significant. In our opinion, this delivers quite a strong result: once we control for idiosyncratic sectoral and country effects we find that the effect of higher firm size on productivity growth is magnified in R\&D intensive sectors. Therefore, we interpret this result as supporting the claim that average firm size matters for growth through its effects on R\&D intensity. This same test leads us also to conclude that there is evidence of causality actually going from firm size to growth.

\footnotetext{
${ }^{18}$ See Appendix 3 for a more formal derivation of this proposition.
} 


\section{Concluding remarks}

European economies display large variations both in terms of sectoral specialization and of size distribution of firms within sectors. Using a data-set of Eurostat, we construct a measure of average firm size and find that differences in the size distribution within sectors play an important role in explaining cross-country differences in average firm size. We study the relationship between firm size distribution and economic growth. We find a positive association between average firm size and productivity growth. We also find evidence that size matters for growth through its influence on innovation activity.

Our results have important bearings on policy. First, policies and institutional settings that, by reducing firms' incentive to grow, induce a steady-state distribution of firms tilted toward the small size, might have a detrimental effect on growth. Among such policies, particularly common are those supporting small firms in terms of tax breaks, subsidies and thresholds below which some regulations, such as employment protection legislation, do not apply.

Second, our results shed light on some stylized pattern of R\&D expenditures at country level. For example, Italy and Spain are the countries with the lower overall average size and are characterize by rates of business sector expenditure in R\&D in relation to GDP approximately half of that of the European Union as a whole. Indeed, according to our findings, a system based on the small scale production might be hill-prepared to fully appropriate the benefits of the current economic phase, characterized by a wave of intense technological changes. 
Appendix 1: Sector Classification for size differential decomposition

\begin{tabular}{lc} 
Table 11: Sectoral classification in section 2 \\
\hline \hline Our Classification & Nace Classification \\
\hline Wood & $\mathrm{dd} 20$ \\
Leather & $\mathrm{dc} 19$ \\
Construction & $\mathrm{f} 45$ \\
Textile & $\mathrm{db} 17-\mathrm{db} 18$ \\
Hotel\&Rest. & $\mathrm{h} 55$ \\
Other Serv. & $\mathrm{o} 90, \mathrm{o} 92, \mathrm{o} 93$ \\
Real Estate & $\mathrm{k} 70-\mathrm{k} 74$ \\
Pap.\&Pub. & $\mathrm{de} 21-\mathrm{de} 22$ \\
Metal Prod. & $\mathrm{dj} 27-\mathrm{dj} 28$ \\
Non-met. Prod. & $\mathrm{di} 26$ \\
Food & $\mathrm{da} 15-\mathrm{da} 16$ \\
Trade & $\mathrm{g} 50-\mathrm{g} 52$ \\
Transport & $\mathrm{i} 63$ \\
Machinery & $\mathrm{dk} 29-\mathrm{dl} 30$ \\
Rubber & $\mathrm{dh} 25$ \\
Other Manuf. & $\mathrm{dn} 36-\mathrm{dn} 37$ \\
Chemical & $\mathrm{dg} 24$ \\
Elett. Mach. & $\mathrm{dl} 31-\mathrm{dl} 33$ \\
Finance & $\mathrm{j} 65-\mathrm{j} 67$ \\
Petroleum & $\mathrm{df} 23$ \\
Transp. Equip. & $\mathrm{dm} 34-\mathrm{dm} 35$ \\
\hline
\end{tabular}

Appendix 2: Data

The data on value added and investment rates are from Eurostat's NewCronos, theme 4, sbs, Annual enterprise statistics available from http://europa.eu.int/new_cronos. The long time series are limited to enterprises with 20 persons employed or more and to the Nace Rev.1 C to F sectors. Growth was calculated as the compound percentage change of real value added per worker between 1998 and 1994 (1989) Descriptive statistics are given in table 12 (by country) and 13 (by sector). Investment rates are simple time average in the period between 1994 and the latest observation in each sector, usually 1996. 
Table 12: Growth rate in average value added per worker (1994-98): by country

\begin{tabular}{l|ccc|c}
\hline \hline ctry & mean & median & st. dev. & N. of sect. \\
\hline de & .0281 & .0312 & .0279 & 18 \\
dk & -.0137 & -.0216 & .0381 & 15 \\
es & -.0028 & -.0048 & .0272 & 15 \\
fi & .0320 & .0207 & .0418 & 18 \\
fr & .0243 & .0217 & .0235 & 17 \\
it & .0324 & .0184 & .0270 & 18 \\
se & -.0058 & -.0105 & .0469 & 17 \\
uk & .0487 & .0419 & .0371 & 18 \\
\hline Total & .0192 & .0164 & .0396 & 136 \\
\hline
\end{tabular}

With respect to Table 1, we use the most disaggregated sectoral classification, that is the two digits level for the Nace rev. 1. The only exception is sector 30 (Computers and Office Machinery), which is lumped together with sector 29 (Machinery and Equipment not otherwise classified), because it employs a very small fraction of the labor force ( 0.2 per cent for the Eu15 aggregate) and is characterized by a rather erratic path for productivity.

The sectors used in the growth regressions are in table 14.

The data on human capital, measured as the average year of schooling in the population over age 25 in 1985, are from the Barro and Lee (1993) database.

The data on R\&D in US sectors - to construct the reverse causality test - are:

1) Share of personnel in RED on total employment, in 1994, constructed as the percentage ratio between "Total $R \& D$ personnel and research scientist and engineers in the business enterprise sector, in full time equivalent" (from OECD's Basic Science and Technology Statistics) and "number of employees" (from Eurostat's NewCronos);

2) RED investment ratio, average between 1990 and 1994, is " R\&D expenditures as a percentage of total physical investment" (from OECD's Main Industrial Indicators);

3) RESD intensity, average between 1990 and 1996, is " R\&D expenditures as a percentage of value added" (from OECD's Main Industrial Indicators).

In Table 8 for the ratio between R\&D and total employment in column 
Table 13: Growth rate in average value added per worker (1994-98): by

\begin{tabular}{l|ccc|c}
\hline sector & \multicolumn{5}{|c}{} \\
\hline Sector (Nace class. number) & mean & median & st. dev. & N. of ctry \\
\hline Food\&Bev. (15) & .0224 & .0165 & .0279 & 5 \\
Textile (17) & .0118 & .0158 & .0223 & 8 \\
Wearing App. (18) & .0353 & .0389 & .0202 & 8 \\
Leather (19) & .0290 & .0219 & .0563 & 6 \\
Wood (20) & .0053 & .0001 & .0166 & 7 \\
Paper (21) & .0088 & .0168 & .0363 & 8 \\
Publishing (22) & -.0043 & -.0102 & .0311 & 8 \\
Chemicals (24) & .0059 & .0156 & .0431 & 8 \\
Rubber (25) & .0011 & .0052 & .0201 & 8 \\
Non metallic prod. (26) & .0060 & .0063 & .0193 & 8 \\
Basic Metals (27) & .0218 & .0275 & .0357 & 8 \\
Fabric. Metal Prod.(28) & .0178 & .0151 & .0334 & 8 \\
Machinery and Comp. (29+30) & .0193 & .0108 & .0407 & 8 \\
Electrical machinery (31) & .0143 & .0225 & .0297 & 8 \\
Communic. Equipment (32) & .0755 & .0645 & .0641 & 7 \\
Precision Instruments (33) & .0255 & .0339 & .0374 & 8 \\
Motor Vehicles (34) & .0261 & .0314 & .0551 & 8 \\
Other Transp.Equip. (35) & .0347 & .0509 & .0572 & 7 \\
\hline Total & .0192 & .0164 & .0395 & 136 \\
\hline
\end{tabular}

1 we label high sectors above the median (1 per cent); in column 2 we label high sectors above 3 per cent and low sectors below 0.6 per cent. For the ratio between $\mathrm{R} \& \mathrm{D}$ expenditure and investment in column 3 we label high sectors above the median (20 per cent); in column 4 we label high sectors above 60 per cent and low sectors below 10 per cent. For the ratio between R\&D expenditures and value added in column 5 we label high sectors above 7 per cent; in column 6 we label high sectors above the 9 per cent $(75$ th percentile) and low sectors below 1.2 per cent. 
Table 14: Data used by country and sectors

\begin{tabular}{lcc}
\hline \hline ctry & sectors (Nace Rev. 1) & N. of sect. \\
\hline de & da15-dm35 & 18 \\
dk & db17-db18, de21-dm35 & 15 \\
es & da15-db18, dd20-dl31, dl33-dm34 & 15 \\
fi & da15-dm35 & 18 \\
fr & db17-dm35 & 17 \\
it & da15-dm35 & 18 \\
se & db17-dm35 & 17 \\
uk & da15-dm35 & 18 \\
\hline Total & & 136 \\
\hline
\end{tabular}

Appendix 3: The reverse causality test

In this appendix we show that the coefficient on the interaction term in equation (8), when also country dummies are included, tell us whether in each country industries that are more $\mathrm{R} \& \mathrm{D}$ intensive grow more the higher firm size.

To this end we use the analogy with the within estimator with a two-way error component (Baltagi, 1995). Let us assume that in each country/sector, the average firm size is the sum of the average firm size in the country (across sectors) and the average firm size in the sector (across countries)

$$
s_{i j}=C_{j}+T_{i} .
$$

Abstracting from the other regressors, the augmented version of equation (8) is

$$
g_{i, j}=\beta_{0}+\beta_{1}\left[s_{i, j} \times D_{i}\right]+\lambda_{i}+\mu_{j}+u_{i, j},
$$

where $\mu^{\prime}$ s are country dummies. The average across sectors is given by

$$
\bar{g}_{\cdot j}=\beta_{0}+\beta_{1}\left[C_{j} \times \bar{D} .+\bar{T} . \times \bar{D} .\right]+\mu_{j}+\bar{u}_{\cdot j},
$$

that across countries is

$$
\bar{g}_{i .}=\beta_{0}+\beta_{1}\left[\bar{C} . \times D_{i}+T_{i} \times D_{i}\right]+\lambda_{i}+\bar{u}_{i},
$$


while the overall mean is

$$
\bar{g} . .=\beta_{0}+\beta_{1}[\bar{C} . \times \bar{D} .+\bar{T} . \times \bar{D} .]+\bar{u} \ldots
$$

Subtracting (A.2) and (A.3) from (A.1), and adding (A.4), gives

$$
\tilde{g}_{i, j}=\beta_{1}\left(D_{i}-\bar{D} .\right)\left(C_{j}-\bar{C} .\right)+\tilde{u}_{i, j},
$$

where $\tilde{g}_{i, j}=g_{i, j}-\bar{g}_{\cdot j}-\bar{g}_{i \cdot}+\bar{g}_{. .}$and $\tilde{u}_{i, j}=u_{i, j}-\bar{u}_{\cdot j}-\bar{u}_{i} .+\bar{u}_{\ldots}$.

According to equation (A.4), $\beta_{1}$ tells whether R\&D intensive sector display higher productivity growth in countries with relatively higher average firm size, or also whether, for given country average firm size, the higher $R \& D$ intensity the strongest the impact of the given firm size on industry growth. 


\section{References}

[1] Amiti, M. (1997), "Specialisation Patterns in Europe", CEPR Discussion Paper, n. 363.

[2] Audtresch, D. (1998), "Agglomeration and the Location of Innovative Activity," CEPR Discussion Paper, n. 1974.

[3] Baltagi, B. (1995) Econometric Analysis of Panel Data, Wiley.

[4] Barro, R.J. and Lee, J. (1993), "International Comparisons of Educational Attainement" Journal of Monetary Economics vol. 32, pp. 218223.

[5] Barro, R.J. and Sala-i-Martin, X. (1995), Economic Growth, McGrawHill.

[6] Bernard, A. B. and Jones, C.I. (1996), Comparing Apples to Oranges: Productivity Convergence and Measurement across Industries and Countries, American Economic Review, vol. 86, pp. 1216-1238.

[7] Bugamelli, M. (1999), "Il modello di specializzazione internazionale dell'area dell'euro e dei principali paesi europei: effetti dellintegrazione e convergenza", mimeo, Bank of Italy.

[8] Budd, C., Vickers, J. and Harris, C. (1993), A Model of the Evolution of Duopoly: does the Asymmetry Between Firms Tend to Increase or Decrease?, Review of Economic Studies, vol. 60, pp. 543-573.

[9] Carree, M. A. and Thurik, A. R.(1998), Small Firms and Economic Growth in Europe, Atlantic Economic Journal, vol. 26, pp.137-146.

[10] Davis, S.J. and Henrekson, M. (1999), "Explaining National Differences in the Size and Industry Distribution of Employment", Small Business Economics, vol. 12, pp. 59-83.

[11] Davis, S.J, Haltiwanger, J. and Schu, S. (1996) "Small Business and Job Creation: Dissecting the Myth and Reassessing the Facts", Small Business Economics, vol. 8, pp. 297-315.

[12] Dunne, T., Roberts, M. and Samuelson, L. (1989) "The Growth and Failure of U.S. Manufacturing Plants," Quarterly Journal of Economics, vol. 104, 671-98. 
[13] de la Fuente, A. and Domenech, R. (2000) "Human capital in growth regressions: how much difference does data quality make", CEPR discussion paper n. 2466.

[14] Ericson, R. and Pakes, A. (1995), "Markov-Perfect Industry Dynamics: A Framework for Empirical Work", Review of Economic Studies, vol.62, pp. 53-82.

[15] Eeckhout, J. and Jovanovic, B. (1998), "Inequality", NBER Working Paper, n. 6841.

[16] Eurostat (1998), "Enterprises in Europe, Data 1994-95", Fifth Report European Commission.

[17] Grossman, G.M. and Helpman, E. (1991), Innovation and Growth in the Global Economy, Cambridge MA, MIT Press.

[18] Guiso, L. and Schivardi, F. (1999), "Information Spillover and Factor Adjustment", CEPR Discussion Paper n. 2289, November.

[19] Jovanovic, B. (1982) "Selection and the Evolution of Industry," Econometrica, vol. 50, 649-70.

[20] Holmstrom, B. and Tirole, J. (1997), "Financial Intermediation, Loanable Funds and the Real Sector, Quarterly Journal of Economics, vol.112, pp. 663-91.

[21] Hopenhayn, H. (1992), "Entry, Exit and Firms Dynamics in Long Run Equilibrium," Econometrica, vol. 60, pp.1127-50.

[22] Kuman, K.B., Rajan, R.G. and Zingales, L. (1999), "What Determines Firm Size?", mimeo.

[23] Lucas, R. (1978), "On the Size Distribution of Business Firms", The Bell Journal of Economics, vol. 9, pp.508-23.

[24] Pakes, A. and McGuire, P. (1994), "Computing Markov-Perfect Nash Equilibria: Numerical Implications of a Dynamic Differentiated Product Model" RAND Journal of Economics, vol.25, pp. 555-589.

[25] Pavitt, K. (1984), "Sectoral Patterns of Technical Change: Towards a Taxonomy and a Theory", Research Policy, vol. 13, pp. 343-74. 
[26] Peretto, P.F. (1998), "Technological Change, Market Rivalry, and the Evolution of the Capitalist Engine of Growth", Journal of Economic Growth, vol. 3, pp. 53-80.

[27] Peretto, P.F. (1999a), "Cost Reduction, Entry, and the Interdependence of Market Structure and Economic Growth", Journal of Monetary Economics, vol. 43 n. 1, pp. 173-195.

[28] Peretto, P.F. (1999b), "Firm Size, Rivalry and the Extent of the Market in Endogenous Technological Change", European Economic Review, vol. 43 n.9, pp. 1747-1773.

[29] Rajan, R. and Zingales, L. (1998), "Financial Dependence and Growth", The American Economic Review, vol. 88, pp. 559-86.

[30] Romer, P.M. (1990), "Endogenous Technological Change", Journal of Political Economy, vol. 98, pp. 71-102.

[31] Sala-i-Martin, X. (1997), "I Just Run Four Million Regressions", NBER Working Paper, n. 6252.

[32] Schumpeter, J. (1934), "Theory of Economic Development", Harvard University Press, Cambridge.

[33] Symeonidis, G. (1996), "Innovation, Firm Size and Market Structure: Schumpeterian Hypotheses and Some New Themes", OECD Economic Department Working Papers, n. 161.

[34] Steindl, J. (1990), "Small and Big Business. Economic Problems of the Size of Firms".

[35] Viner, J. (1932), "Cost Curves and Supply Curves", Zeitshrift fur Nationalokonomie, vol. 3, pp. 23-46.

[36] Traù, F. (1999), "Il riemergere della small scale production nei paesi industriali", in "La questione dimensionale nell'industria italiana", F. Traù (ed.), Bologna, il Mulino. 